\title{
Lipophilicity of Opioids Determined by a Novel Micromethod
}

\author{
Fedor Medzihradsky, Paul J. Emmerson, and Carol A. Mousigian \\ Departments of Biological Chemistry and Pharmacology, University of Michigan Medical School, \\ Ann Arbor, Michigan, U.S.A.
}

\begin{abstract}
The lipophilicity of various $\mu$-selective opioids was determined by measuring their distribution between $n$-octanol and Tris. $\mathrm{HCl}$ buffer, $\mathrm{pH} 7.4$, by a procedure requiring submicromolar concentrations (submilligram amounts) of the compounds. After partitioning at $25^{\circ} \mathrm{C}$, the concentration of opioids in the aqueous phase was quantified by their displacement of bound $\left[{ }^{3} \mathrm{H}\right]$ Tyr-Ala-Gly-(Me)Phe-Gly-ol (DAMGO) from opioid receptor in brain membranes. The obtained distribution coefficients $\left(\log \mathrm{P}_{\mathrm{app}}\right)$ agreed well with respective values determined previously with other, less sensitive or more cumbersome, methods of quantitation. The procedure is precise and versatile, and offers the routine assessment of lipophilicity as part of the in vitro characterization of opioids frequently available in limited quantities. In principle, the method is applicable to any compound whose binding to its receptor is quantifiable.
\end{abstract}

Key Words: Opioids; Lipophilicity; Octanol-water partition coefficient; Opioid receptor binding

\section{INTRODUCTION}

In numerous studies, the lipophilicity of opioids has been related to the effectiveness of their pharmacologic action. For example, lipophilic opioids were equipotent when given either systemically or intrathecally, whercas hydrophilic opioids had a much higher potency following intrathecal administration (Herz and Teschemacher, 1971). Furthermore, the influence of lipophilicity on the time course of pharmacologic action and on the receptor kinetics of opioids has been described (Hambrook and Rance, 1976). The lipophilicity of opioids has previously been determined by their distribution between aqueous medium and organic solvents using different methods of quantitation, including spectrophotometry (Herz and Teschemacher, 1971), electrometric titration (Kaufman et al., 1975), and the measurement of radioactivity (Misra et al., 1974). A drawback of these procedures is either the

From the Departments of Biological Chemistry and Pharmacology, University of Michigan Medical School, Ann Arbor, Michigan, U.S.A.

Address reprint requests to: Dr. Fedor Medzihradsky, Department of Biological Chemistry, University of Michigan Medical School, Medical Science Bldg. I, Ann Arbor, MI 48109, U.S.A. Received May 7, 1991; revised and accepted August 7, 1991.

Journal of Pharmacological and Toxicological Methods 27, 67-69 (1992)

(C) 1992 Elsevier Science Publishing Co., Inc.,

655 Avenue of the Americas, New York, NY 10010 lack of sensitivity or the required availability of the tested opioids in radiolabeled form. On the other hand, we have established a procedure in this study that provides distribution coefficients for opioids present at submilligram amounts, offering thereby routine applicability and a high degree of accuracy and precision.

\section{METHODS}

$\left[{ }^{3} \mathrm{H}\right] \mathrm{Tyr}-\mathrm{Ala}-\mathrm{Gly}$-(Me)Phe-Gly-ol (DAMGO) and $\left[{ }^{3} \mathrm{H}\right]$ etorphine were purchased from Amersham Corporation, and the unlabeled opioids were obtained through the Narcotic Drug and Opiate Peptide Basic Research Center at the University of Michigan Medical School. Isolation of membranes from rat and monkey brain were carried out as described (Clark et al., 1988).

For partitioning, the tested opioid was routinely dissolved at a concentration of $3 \mu \mathrm{M}$ each in $50 \mathrm{mM}$ Tris $\cdot \mathrm{HCl}, \mathrm{pH} 7.4$ that had been saturated at $25^{\circ} \mathrm{C}$ with $n$-octanol, and in $n$-octanol preequilibrated with the Tris buffer. Alternatively, salt forms of opioids can be dissolved in the buffer, and bases in octanol. Equal volumes of the aqueous phase and $n$-octanol were shaken at $25^{\circ} \mathrm{C}$ in a small separatory funnel or a tube for $60 \mathrm{~min}$ at approximately 140 strokes per min (Eberbach horizontal shaker). The two phases were allowed to 
separate for $30 \mathrm{~min}$, the organic layer was aspirated, and an aliquot of the lower aqueous layer was collected into a glass tube. The tube was centrifuged at $1000 \mathrm{~g}$ for $10 \mathrm{~min}$ at $25^{\circ} \mathrm{C}$ to complete the phase separation. After renewed aspiration of the octanol phase, samples of the aqueous layer were removed and subjected to the opioid-receptor binding assay. Necessary dilutions in the assay were made using octanol-equilibrated Tris $\cdot \mathrm{HCl}$ buffer, $\mathrm{pH} 7.4$.

Considering the $\mu$ receptor selectivity of the tested opioids, their concentration in the aqueous layer before and after partitioning was quantified by displacement of $0.5 \mathrm{nM}\left[{ }^{3} \mathrm{H}\right] \mathrm{DAMGO}$ as described (Clark et al., 1988). Alternatively, particularly for nonselective opioids, the displacement of $0.5 \mathrm{nM}\left[{ }^{3} \mathrm{H}\right]$ etorphine can be used for quantitation. Receptor-specific binding was determined with an appropriate excess of the respective unlabeled opioid. The inhibition of radioligand binding was standardized with five different concentrations of the tested opioid. The $\mathrm{IC}_{50}$ values and slope factors were determined by linear regression analysis from Hill plots, relating percent inhibition of radioligand binding to five concentrations of the competing opioid. The correlation coefficient $\left(r^{2}\right)$ of the linear regression was higher than 0.98 in all cases. From the obtained $\mathrm{EC}_{50}$ plots, the inhibition of radioligand binding by the tested opioid was related to its concentration in the aqueous phase before and after partitioning, and expressed as apparent partition coefficient $\left(\log \mathrm{P}_{\mathrm{app}}\right)$. The latter parameter reflects the partitioning of free base and of acid salt between the organic solvent and aqueous phase.

\section{RESULTS}

As shown in Table 1, the procedure described here provides partition coefficients with a degree of precision comparable to that obtained using automated highperformance liquid chromatography (Garst and Wilson, 1984). The major feature of the method is its adaptability to minute amounts of opioids: the partitioning of a $10 \mathrm{~mL} 1 \mu \mathrm{M}$ solution of an opioid with a molecular weight of 300 requires $3 \mu \mathrm{g}$ of the compound. Furthermore, assuming that the tested opioid displaces [ $\left.{ }^{3} \mathrm{II}\right] \mathrm{DAMGO}$ or $\left[{ }^{3} \mathrm{H}\right]$ etorphine in the binding assay with an $\mathrm{IC}_{50}$ of $100 \mathrm{nM},<1 \mu \mathrm{g}$ of the compound is sufficient to obtain a concentration-binding inhibition plot with five different concentrations, each run in duplicate. Actually, the limiting factors of sensitivity in applying this procedure are the availability of suitable containers for the partitioning of small volumes, and the weighing of submilligram amounts of the sample. The required sensitivity of the procedure is adjustable by the appropriate selection of 1) partition volumes, 2) initial concentration of opioids, and 3) dilutions of the partitioned aqueous phase subjected to quantitation.

There was a remarkably good agreement between the partition coefficients determined in this study and those obtained previously with different methods of quantitation (Table 1). The low value for etorphine reported in one of the referenced studies (Herz and Teschemacher, 1971) is puzzling. Considering the structural features of the opioids listed in Table 1, the values obtained in this work and in the detailed investigation by Kaufman (1978) seem more appropriate. In the latter study, the strong influence of temperature

TABLE 1 Lipophilicity of Opioids: Octanol-Water Partition Coefficients Determined by Various Methods of Quantitation

\begin{tabular}{|c|c|c|c|}
\hline \multirow[b]{2}{*}{ Opioid } & Determined & Reported & \multirow[b]{2}{*}{ Reference } \\
\hline & \multicolumn{2}{|c|}{ Log $\mathrm{P}_{\mathrm{APP}}$ Values } & \\
\hline Sufentanil & $\begin{array}{c}3.55 \\
( \pm 0.02)\end{array}$ & 3.24 & Lcyson ct al. (1983) \\
\hline Etorphine & $\begin{array}{c}2.79 \\
( \pm 0.02)\end{array}$ & $1.86 ; 2.76$ & Herz and Teschemacher (1971); Kaufman (1978) \\
\hline Levallorphan & $\begin{array}{c}2.19 \\
( \pm 0.02)\end{array}$ & 2.03 & Kaufman et al. (1975) \\
\hline Methadone & $\begin{array}{c}1.82 \\
( \pm 0.05)\end{array}$ & $1.63 ; 1.74$ & Kaufman et al. (1975); Misra et al. (1974) \\
\hline Naloxone & $\begin{array}{c}1.04 \\
( \pm 0.08)\end{array}$ & $1.12 ; 0.73$ & Kaufman et al. (1975); Misra et al. (1974) \\
\hline Levorphanol & $\begin{array}{c}0.96 \\
( \pm 0.07)\end{array}$ & $0.62 ; 0.94$ & Kaufman et al. (1975); Misra et al. (1974) \\
\hline Morphine & $\begin{array}{l}-0.21 \\
( \pm 0.01)\end{array}$ & $0.068 ; 0 ;-0.12$ & $\begin{array}{l}\text { Herz and Teschemacher (1971); Kaufman } \\
\text { (1978); Misra et al. (1974) }\end{array}$ \\
\hline
\end{tabular}

Shown are mean values and \pm SEM (in parentheses) of four determinations of $\log P_{a p p}$. The receptor assay was carried out with [ ${ }^{3} \mathrm{H}$ ]DAMGO and several concentrations of the partitioned opioid, as described in the Methods section. Also listed are published partition coefficients obtained with different methods of quantitation. 
and $\mathrm{pH}$ on the partition coefficient for etorphine was emphasized. Unfortunately, the provided information on specified conditions under which some reported partition coefficients were obtained is incomplete.

\section{DISCUSSION}

In addition to the established significance of lipophilicity in the function of opioids, its role in the development of novel opioids has recently been highlighted. Based on the number of positive charges and the presence of hydrophobic amino acid residues, such as naphthylalanine, the lipophilicity of newly synthesized opioid peptides was influential in targeting these compounds to the central nervous system or periphery and determining their receptor binding selectivity (Schiller et al., 1989). Thus, the multifaceted significance of lipophilicity points to the need to consider it as an important molecular property of opioids. The method for its quantitation described here offers a unique combination of sensitivity, accuracy, precision, and versatility. By selecting the appropriate radiolabeled ligand in the binding assay, the procedure becomes applicable to opioids of different receptor selectivity. For example, the displacement of $\left[{ }^{3} \mathrm{H}\right]$ etorphine allows the quantitation of either $\mu, \delta$, or $\kappa$ opioids in the aqueous phase following partitioning. Alternatively, if dealing with selective opioids, radiolabeled DAMGO, DPDPE, or U69,593 can be used (Clark et al., 1988). Conveniently, the procedure can be carried out in conjunction with the determination of receptor binding of the tested opioid: different aliquots of a common stock solution can be used to obtain a measure of binding affinity $\left(\mathrm{IC}_{50}\right)$ and lipophilicity $\left(\log \mathrm{P}_{\mathrm{app}}\right)$. Significantly, the routine applicability of the method provides an additional biochemical determinant in the preclinical evaluation of novel opioids frequently available in limited amounts (Medzihradsky, 1987).
The authors thank R. McLaughlin for expert secretarial assistance. This work was supported by USPHS Grant DA 00254.

\section{REFERENCES}

Clark MJ, Carter BD, Medzihradsky F (1988) Selectivity of ligand binding to opioid receptors in brain membranes from the rat, monkey and guinea pig. Eur J Pharmacol 148:343-351.

Garst JE, Wilson WC (1984) Accurate, wide-range, automated, highperformance ligand chromatographic method for the estimation of octanol/water partition coefficients: effect of chromatographic conditions and procedure variables on accuracy and reproducibility of the method. J Pharmacol Sci 73:1616-1623.

Hambrook JM, Rance MJ (1976) The interaction of buprenorphine with the opiate receptor: Lipophilicity as the determining factor in drug-receptor kinetics. In Opiates and Endogenous Opioid Peptides. Ed.. HW Kosterlitz. Amsterdam: North Holland Publishing Company, pp. 295-301.

Herz A. Teschemacher H-I (1971) Activities and sites of antinociceptive action of morphine-like analgesics and kinetics of distribution following intravenous, intracerebral and intraventricular application. Adv Drug Res 6:79-119.

Kaufman JJ (1978) Recent physicochemical and quantum chemical studies on drugs of abuse and relevant biomolecules. Natl Inst Drug Abuse Res Monogr 22:250-277.

Kaufman JJ, Semo NM, Koski WS (1975) Microelectrometric titration measurement of the $\mathrm{pKa}$ 's and partition and drug distribution coefficients of narcotics and narcotic antagonists and their $\mathrm{pH}$ and temperature dependence. J Med Chem 18:647-655.

Leyson JE, Commeren W, Niemegeers CJE (1983) [ $\left.{ }^{3} \mathrm{H}\right]$ Sufentanil, a superior ligand for $\mu$-opiate receptors: Binding properties and regional distribution in rat brain and spinal cord. Eur $J$ Pharmacol 87:209-225.

Medzihradsky F (1987) Novel biochemical determinants in the preclinical evaluation of opiates. Natl Inst Drug Abuse Res Monogr 76:349-355.

Misra AL, Pontani RB, Mulé SJ (1974) Pharmacokinetics and metabolism of $\left[{ }^{3} \mathrm{H}\right]$ thebaine, Xenobiotica $4: 17-32$.

Schiller PW, Nguyen TM-D, Chung NN, Dionne G, Martel F (1989) Peripheral antinociceptive effect of an extremely $\mu$-selective polar dermorphin analog (DALDA). In The Internatl. Narc. Res. Conf. (INRC) '89. Eds, R. Quirion, K Jhamandas, C Gianoulakis. New York, NY: Alan R. Liss Publishing Co., pp. $53-56$. 